\title{
Speculative Study on the Combination of Education Poverty Alleviation and Rural Revitalization Strategy in Ethnic Areas
}

\author{
Based on the Analysis of Liangshan Prefecture Policy Text*
}

\author{
Meipeng Wang \\ School of Management \\ Southwest Minzu University \\ Chengdu, China
}

\begin{abstract}
Since the country put forward the precise poverty alleviation, education poverty alleviation has become an important and effective way for China to get rid of poverty. Education poverty is the key reason for poverty alleviation and poverty-returning in ethnic areas. After the rural revitalization strategy is put forward, it can be seen that there is a great correlation between the poverty alleviation and rural revitalization strategy from the literal expression. This paper seeks for the symbiosis points by rationalizing the interest subjects, education poverty alleviation theory and rural revitalization strategy in the process of education poverty alleviation and rural revitalization in ethnic areas. Through the combing research of the relevant policy texts of the representative Liangshan Yi Autonomous Prefecture, this paper plans to find out the intrinsic link between education poverty alleviation and rural revitalization in ethnic areas, and clarify the commonalities and possible combinations of education poverty alleviation and rural revitalization strategy in ethnic areas to construct a rural symbiosis development model in ethnic areas, and to clarify the concrete form of the combination of education poverty alleviation and rural revitalization strategy in the symbiosis pattern of ethnic areas.
\end{abstract}

Keywords - ethnic areas; education poverty alleviation; rural revitalization strategy; combination; policy text analysis

\section{INTRODUCTION}

China is a multi-ethnic country with a complex land area with 55 ethnic minorities and the Han nationality. The ethnic minorities mainly live in China's border areas, which account for almost two-thirds of our territory. Due to geographical and environmental factors, the economies of these regions are generally backward, human capital is relatively poor and the quality of life is low. In order to solve these problems, the Party and the Country led by General Secretary Xi Jinping adhering to the initial heart and mission of "seeking happiness for the Chinese people and seeking rejuvenation for the Chinese nation", have put forward precise poverty alleviation for the particularity of ethnic areas, and the

*This article is supported by the Project: Southwest Minzu University Graduate Innovation Research Project. Project number: CX2019SZ32. education poverty alleviation is an important and effective approach to poverty alleviation in ethnic minority areas. The region's overall plan is to lift poverty and achieve an important effective path to poverty alleviation. The country's overall plan is to achieve comprehensive poverty alleviation by 2020 . However, from the actual situation of poverty alleviation, the problem of returning to poverty after poverty alleviation is more prominent. Precise poverty alleviation is a long-term problem, therefore, many scholars have suggested that education is the fundamental path to block intergenerational transmission and return to poverty. General Secretary $\mathrm{Xi}$ Jinping proposed the rural revitalization strategy in the party's 19th National Congress report on October 18, 2017. The 19th National Congress report pointed out that agriculture, rural areas and farmers are fundamental issues for the people's livelihood, and efforts should be intensified to develop rural areas. The central and local governments should actively promote the "new urbanization" and "beautiful countryside" construction. On January 2, 2018, the State Council issued the central No.1 file "The Central Committee of the Communist Party of China and the State Council on Implementing the Strategy for Rural Revitalization". By combing the articles on education poverty alleviation and rural revitalization strategies, it is found that the research on education poverty alleviation is relatively mature, but the research literature on rural revitalization strategy is not mature enough. The literature on rural revitalization from the perspective of education is relatively rare. There is less research literature from the perspective of combining education poverty alleviation and rural revitalization strategy, but it is undeniable that there is a great connection between precise poverty alleviation and rural revitalization strategies in ethnic areas, for example, the background, social form, purpose, time, method and path of the implementation of the two will overlap, and to a large extent, they supplement and contain each other. This thesis attempts to find the potential combination of education poverty alleviation and rural revitalization strategy in ethnic areas based on previous studies. It also confirms the correctness of the research through the policies implemented so far in the Liangshan Yi 
Autonomous Prefecture, which represents the ethnic minority areas, and provides a model for the implementation of education poverty alleviation and rural revitalization strategies in China's broad ethnic areas.

\section{THE THEORETICAL BASIS FOR THE COMBINATION OF EDUCATION POVERTY ALLEVIATION AND RURAL REVITALIZATION STRATEGY IN ETHNIC AREAS}

Through combing the literature related to education poverty alleviation theory, it is found that domestic and foreign scholars mainly study education poverty alleviation theory based on economics, sociology and education. The theory of education poverty alleviation originated from foreign anti-poverty theory, from the perspective of economics. This theory put forward that education can help poverty-stricken areas out of poverty. The most representative figure in this theory is Rosenstein Rodin, who put forward the theory of the big-push in 1943, arguing that poverty-stricken areas must achieve poverty alleviation and rejuvenation through State-led ways to invest in povertystricken areas [1]. Domestic scholars draw on foreign antipoverty theory and combine their specific national conditions to conclude the main cause of poverty is due to the poor areas of regional resources and poor infrastructure. Yang Nengliang, Huang Peng and other scholars believe that it is necessary to increase the infrastructure construction in poverty-stricken areas, especially to increase the government's investment in education, to improve the quality of the poor in ethnic areas and the economic and cultural environment, and promote the rapid realization of poverty alleviation in poverty-stricken areas. [2]. In fact, based on the author's own understanding of education poverty alleviation and rural revitalization strategy, the rural revitalization strategy's requirements include the results of education poverty alleviation and far beyond the results of education poverty alleviation. Nowadays, the education poverty alleviation strategy is to promote and ensure the realization of rural revitalization strategy. Education poverty alleviation is the foundation of the rural revitalization strategy. Some of the studies are based on the perspective of human capital and the most representative of this research is the American scholar Schultz, who proposed the human capital theory. Schultz believes that the main cause of regional poverty is not economic factors, but human quality. That is to say, he believes that the main factors restricting the development of the regional economy are not the poor nature of natural resources and the natural environment. The main reason for poverty in poverty-stricken areas is not the lack of material resources and it is because of the low and backward human quality. Therefore, in order to help the poor areas get rid of poverty and then realize rural revitalization, it is necessary to increase investment in education, develop education and improve the quality of human resources, which is an indispensable measure for the sustainable development of regions and villages. [3]. There are a lot of domestic studies on the lack of human capital leads to poverty. He Jiali, Cha Fang and others investigated the poverty alleviation effect of 18 poverty-stricken counties in Shaanxi Province, and empirically study Schultz's human capital theory and education poverty alleviation theory. And they think that education poverty alleviation can promote the development of underdeveloped areas to developed areas, and at the same time, it can improve the human capital of poverty-stricken areas, change the minds and the development concept of local people, optimize the local economic development structure, and alleviate the environmental pressure caused by the local mode of inefficient and rough development. [4] From the above research on the theory of education poverty alleviation, it is clear that the causes of poverty in povertystricken areas can be roughly summarized as the poor environment of resources in poor areas and the low quality of human capital, and these two situations are more prominent in the ethnic areas of China. Compared with developed areas even ordinary non-minority areas, the resources are scarcer and education is even more backward. In the report of the 19th National Congress of the Communist Party of China, the rural revitalization strategy is described in a new and systematic way. The general requirement for the rural revitalization strategy is "booming industry, livable environment, civilized local customs as well as wealthy life". Therefore, it can be seen from the theory that there are many potential points of integration in education poverty alleviation and rural revitalization strategies in ethnic areas.

\section{THE REALISTIC BASIS FOR COMBINING EDUCATION \\ POVERTY ALLEVIATION AND RURAL REVITALIZATION STRATEGY IN ETHNIC AREAS}

From the perspective of political system, ethnic areas are basically implementing the system of regional ethnic autonomy. From the perspective of economic development, the vast ethnic areas are generally poor, and even some counties and cities are in deep poverty, such as Butuo County and Zhaojue County etc. in Liangshan Prefecture. From the perspective of the environmental characteristics, the ethnic areas are basically border areas in China's territory with extremely awful environment and climatic condition, and the development of rural villages is also backward. The humanities quality in ethnic areas generally shows low quality, backward ideas and unable to keep up with the requirements of China's socialist construction in the new era. The education poverty alleviation strategies in the national poverty alleviation strategy and the implementation of the rural revitalization strategy have a symbiotic soil based on these common factors. This kind of situation is analyzed from the following aspects.

\section{A. Low Level of Education and Backward Villages in Symbiosis in Ethnic Areas}

The unique low level of education and the low level of rural development in ethnic areas provide the soil for their symbiosis. This situation is a common problem in ethnic areas of China, although there is a gap between the development level of education and the development level of rural areas due to the differences in specific places, the problems and development situation of ethnic areas are more similar in terms of universality, and the development mode has a great possibility of reference. Taking Liangshan Prefecture as an example: Liangshan Prefecture is located in the southwest of Sichuan province, China. It is mainly a 
settlement of the $\mathrm{Yi}$ nationality. The Liangshan Yi Autonomous Prefecture covers an area of 60,400 square kilometers and consists of 17 counties and cities. The countryside is widely distributed, mainly in agriculture and animal husbandry, and the traffic there is closed. In addition to the five counties and cities located in the Anning River Valley (Xichang, Mianning, Dechang, Huili, Huidong and Ningnan), the other 12 counties are state-level deep poverty counties. It can be seen that basic education, vocational education and higher education in ethnic areas are at the lowest level of education in the country. Due to the lack of educational resources and people's backward ideas, education and rural economic development present the "Matthew effect". Both education and rural development have entered an infinite loop. [5] With the help of national policies, regions that have achieved good development have made their own development better through internal forces. However, regions that have suffered from poor development haven't been able to develop in the social context of the country's vigorous efforts to fight poverty. Many scholars have long proposed ideas like "He who cures poverty must first cure ignorance" and "Teaching associates to fish rather than simply giving them fish". Education has the function of blocking intergenerational transmission of poverty. Therefore, from the unique humanistic environment of ethnic areas, it can be seen that the only way to realize the longterm strategy of rural revitalization is to increase investment in education and improve the quality of people in ethnic areas.

\section{B. Major Requirements for Rural Revitalization Strategy}

The report of the 19th National Congress pointed out that the implementation of the rural revitalization strategy is to adhere to the principle of giving priority to the development of agriculture and rural areas to accelerate the modernization of agriculture and rural areas. The general requirements are "booming industry, livable environment, civilized local customs, effective governance and wealthy life". The rural revitalization strategy is the requirement for socialism to enter a new era to build a well-off society in an all-round way. The importance of education is seen in the five general requirements of the rural revitalization strategy. The booming industry is the basis for the realization of the rural revitalization strategy in the ethnic areas, and the booming industry in the new socialist era won't be a traditional industry but will certainly be a modern industry. The important feature of the new modernization industry is to improve the efficiency of the industry and promote the transformation of traditional industries to the modern industry through science, technology, systems, organization and management innovation. However, in the backward ethnic areas, education is inseparable to achieve the purpose of industrial prosperity because the new type of labor and technical personnel required by the new modernization industry requires at least more high-quality human capital than the present. [6] Livable environment is the quality guarantee for realizing the rural revitalization strategy. The changes in the main social contradictions in the new era of socialism have made rural farmers demand higher quality of life. Even in ethnic areas with backward economic development, people are no longer just to meet the needs of life, but to meet the spiritual needs, the need for a more beautiful living environment, which requires education to play its guiding role: establish environmental awareness through education, realize the harmonious coexistence of man and nature and jointly build beautiful countryside. The construction of rural civilization has become more urgent in ethnic areas. Due to the concentration and mixed living of ethnic minorities in various ethnic areas and the low level of education, the construction of civilized civilization is very low. In addition to increasing investment in public facilities, education is also needed to fundamentally solve backward habits and ideas. Effective governance is an inevitable requirement for the implementation of the rural revitalization strategy. The social, environmental and economic conditions in the ethnic areas are very different from the existing ones. To this end, it is necessary to effectively develop local education, train more talents who are familiar with their own ethnic groups and regions, and establish and improve a modern rural social governance and management system featuring government responsibility, social coordination, public participation and law guarantee. The demand for wealthy life is the long-term strategic goal of the rural revitalization strategy. At this stage, China's vast ethnic regions are still in the final stage of poverty alleviation. Education is indispensable in the poverty alleviation stage and even after the poverty alleviation strategy to achieve rural revitalization strategy.

\section{Requirements for the Simultaneous Synchronization of Ethnic Areas and Society}

The new generation of leadership collectives with General Secretary Xi Jinping as the core proposes to build a well-off society in an all-round way. On the road to prosperity, no one can be left behind. However, throughout the ethnic areas in China, there is a big gap between the political, economic, cultural, urban and rural construction and the current society. In particular, the general poverty prevents ethnic areas from developing in step with the current society. According to the data released by the National Bureau of Statistics in 2018, the per capita disposable income of poor rural residents is 10,371 yuan, an increase of 994 yuan over the previous year. The per capita disposable income of rural residents in deep poverty-stricken areas is 9668 yuan, and the per capita disposable income of rural residents in the "three districts and three states" is 9,796 yuan. However, the disposable income of rural residents in China in 2018 is 14,617 yuan, which is much higher than the disposable income of rural residents in poverty-stricken areas. [7] From the simple disposable income of rural residents, it can be seen that there is indeed a big gap between rural areas in poverty-stricken areas and China's current rural development, not to mention the situation that there is a great gap between the development of poverty-stricken areas and deep-poor areas in ethnic areas and national strategies. Therefore, there is a strong urgency for the development of ethnic minority areas to synchronize with the social development. And it is precisely because of such urgency that there is a great space for the symbiotic combination of 
national strategy service, educational poverty alleviation and rural revitalization strategy.

\section{ANALYSIS BASED ON THE POLICY TEXT OF LIANGSHAN PREFECTURE}

The policy text shows the government's attitude and the direction of the future. The national and government policies reflect the basic concept of national governance to get rid of poverty and realize the rural revitalization strategy. The analysis of the policy text itself can clarify the government's policy orientation and understand the government policy means. On the basis of implementing the national poverty alleviation work and the rural revitalization strategy, the Liangshan Prefecture government, under the guidance of the national and provincial government policies, combined with the actual situation of its own ethnic areas, issued documents for the education poverty alleviation and rural revitalization strategy, for example, "The Decision of the Liangshan State Committee of the Communist Party of China to Focus on Winning the Poverty Alleviation and Development to Ensure the Simultaneous Completion of A Well-off Society in An All-round Way", "Notice on Printing and Implementing the Outline of the National Science Quality Action Plan for Liangshan Prefecture (2016-2020)", "Implementation Plan for Poverty Alleviation Through Education in Sichuan (2017-2020)", "Implementation Opinions of the Liangshan Prefecture People's Government of the Liangshan Prefecture Committee on Promoting the Talent Revitalization Project in Deep Poverty Counties" and so on. Some of these policy texts reflect the combination of education poverty alleviation and rural revitalization. For example, in the "Implementation Opinions of the Liangshan Prefecture People's Government of the Liangshan Prefecture Committee on Promoting the Talent Revitalization Project in Deep Poverty Counties", it directly reflects the combination of the two implementations. [8] Comprehensively improve the educational development level of poverty-stricken areas and improve the quality of the poor to complete the first step of the rural revitalization strategy and then fundamentally block the intergenerational transmission of poverty in poor ethnic areas through education to realize rural revitalization.

From the above policy texts, the current practice of combining education poverty alleviation and rural revitalization strategies in ethnic areas and the enlightenment to the future are summarized. From the policy text and realistic practices, it is proposed that the education poverty alleviation and rural revitalization strategies in ethnic areas should adhere to the five adherence principles. First of all, adhere to the preferential principle. Due to the special development of ethnic areas, the foundation there is weak and can't adapt to the policies implemented in the unification of ordinary non-ethnic areas. Therefore, in order to realize the strategy of poverty alleviation and rural revitalization, it is necessary to adopt the special development policies of ethnic areas. And at the same time, the most important thing is that the state must adhere to policies, manpower, material resources, financial resources, etc. to the ethnic areas, and through preferential policy support to make up the inherent development shortcomings of ethnic areas, get rid of poverty and achieve rural revitalization; secondly, adhere to the central and provincial driven by the government. The social and economic development of ethnic areas is backward, the local government's fiscal revenue is small, and even some national governments' fiscal deficits, in the case of their own development and the different non-ethnic areas, and it is unrealistic for them to rely on local governments to solve their own problems. Therefore, in ethnic areas with special social development, it is necessary to stick to the model of provincial government and national government taking the lead and local government cooperating with implementation; thirdly, adhere to the principle of gathering strengths to deal with important matters. The advantage of China's socialist system is to gather strengths to deal with important matters, which is also China's unique institutional advantage. I want to go to one place and go to the other place. Think in the same direction and strive in the same direction. Many successful cases of concentrating efforts to accomplish major tasks can be seen in the history. In the future, the poverty alleviation and rural revitalization strategy in ethnic areas should stick to this principle as always. Fourthly, adhere to the principle of benefiting the people. The mission and initial intention of the Communist Party of China is to "seek happiness for the Chinese people and seek rejuvenation for the Chinese nation." Whether it is education poverty alleviation or rural revitalization strategy, it's necessary to adhere to the principle of benefiting the people. Effectively let the poor rural population in the ethnic areas enjoys the welfare of the country's economic development and truly feel the happiness of building a well-off society in an all-round way by 2020; fifthly, adhere to the principle of counterpart assistance. The model of counterpart assistance is used in many practical problems in China and there are many successful cases. It is a good model for the weak economy and the lagging development ethnic areas. Counterpart assistance can make up for the shortcomings of regional and urban-rural imbalances in China, and give full play to its advantages to let the first-developed and first-rich regions drive post-development and backward areas and help each other in ethnic areas. Counterpart assistance has great practical significance on the combination of education poverty alleviation and rural revitalization strategy.

\section{CONCLUSION}

In summary, through the analysis of the theoretical foundation of education poverty alleviation and rural revitalization strategy, coupled with the unique social development and reality in ethnic areas, it is apparent that the "poverty" of education corresponds to the rural area's falling behind. Education shoulders heavy responsibility in terms of poverty alleviation strategy. As to the rural revitalization strategy, education also bears heavy responsibility. The implementation of precise poverty alleviation and rural revitalization strategies is an important strategic measure for the country to complement the weak points of building a well-off society in an all-round way and solve the problems of unbalanced and insufficient development in the new era. The education for poverty alleviation and rural revitalization strategy in ethnic areas are highly coincident in their goals. The function of education to alleviate poverty and block the 
intergenerational transmission of poverty is a long-term guarantee for rural revitalization and rural revitalization. Therefore, in ethnic areas, the rural revitalization strategy is inseparable from education poverty alleviation. The rural revitalization strategy and education poverty alleviation are mutually reinforcing. They have the same soil background and there are many symbiotic bonds between them. In the future rural revitalization strategy of ethnic areas, the method of combination of education poverty alleviation and rural revitalization and rural revitalization through education, is a great development pattern for rural revitalization.

\section{REFERENCES}

[1] Rosenstein Rodin. Industrialization in Eastern and South Eastern European Countries [J]. Journal of Economics, 1943: 6-9.

[2] Yang Nengliang, Huang Peng. Education Poverty Alleviation Finance Thinking of Poverty Alleviation in China [J]. Journal of Fujian Finance and Accounting Management College , 2002 (1):14. (in Chinese)

[3] Liu Weizhong. Study on the Pattern and Countermeasures of Poverty Alleviation and Development in Rural Areas in Xinjiang in the New Stage [D]. Urumqi: Xinjiang Agricultural University, 2010. (in Chinese)

[4] He Jiali, Zha Fang, Chen Xuao. An Empirical Analysis of the Effect of Human Capital Theory Education on Poverty Alleviatio-Based on the Investigation of Education Poverty Alleviation Effect in 18 Poverty Counties in 7 Cities of Shaanxi Province [J]. Tangdu Journal, 2015 (3). (in Chinese)

[5] Zhan Guohui, Zhang Xinwen. Study on the Symbiotic Development of Traditional Villages Under the Rural Revitalization-Based on the Analysis of Jiangsu S County [J]. Realistic, 2017, (11): 71-84. (in Chinese)

[6] Wen Tiejun, Yang Shuai. Rural Governance and Rural Development Against the Background of Social Structure Changes in Rural China [J]. Theoretical Discussion, 2012, (6): 76-80. (in Chinese)

[7] National Bureau of Statistics
[EB/OL] http://www.stats.gov.cn/tjsj/tjgb/ndtjgb/

[8] Liangshan Yi Autonomous Prefecture People's Government [EB/OL]. http://www.lsz.gov.cn 